This item was submitted to Loughborough's Research Repository by the author.

Items in Figshare are protected by copyright, with all rights reserved, unless otherwise indicated.

\title{
Enterprise design information: the key to improved competitive advantage
}

PLEASE CITE THE PUBLISHED VERSION

http://dx.doi.org/10.1080/09511920110040557

PUBLISHER

(c) Taylor \& Francis

VERSION

AM (Accepted Manuscript)

LICENCE

CC BY-NC-ND 4.0

REPOSITORY RECORD

Harding, Jennifer A., and K. Popplewell. 2019. "Enterprise Design Information: The Key to Improved Competitive Advantage". figshare. https://hdl.handle.net/2134/9806. 
This item was submitted to Loughborough's Institutional Repository (https://dspace.lboro.ac.uk/) by the author and is made available under the following Creative Commons Licence conditions.

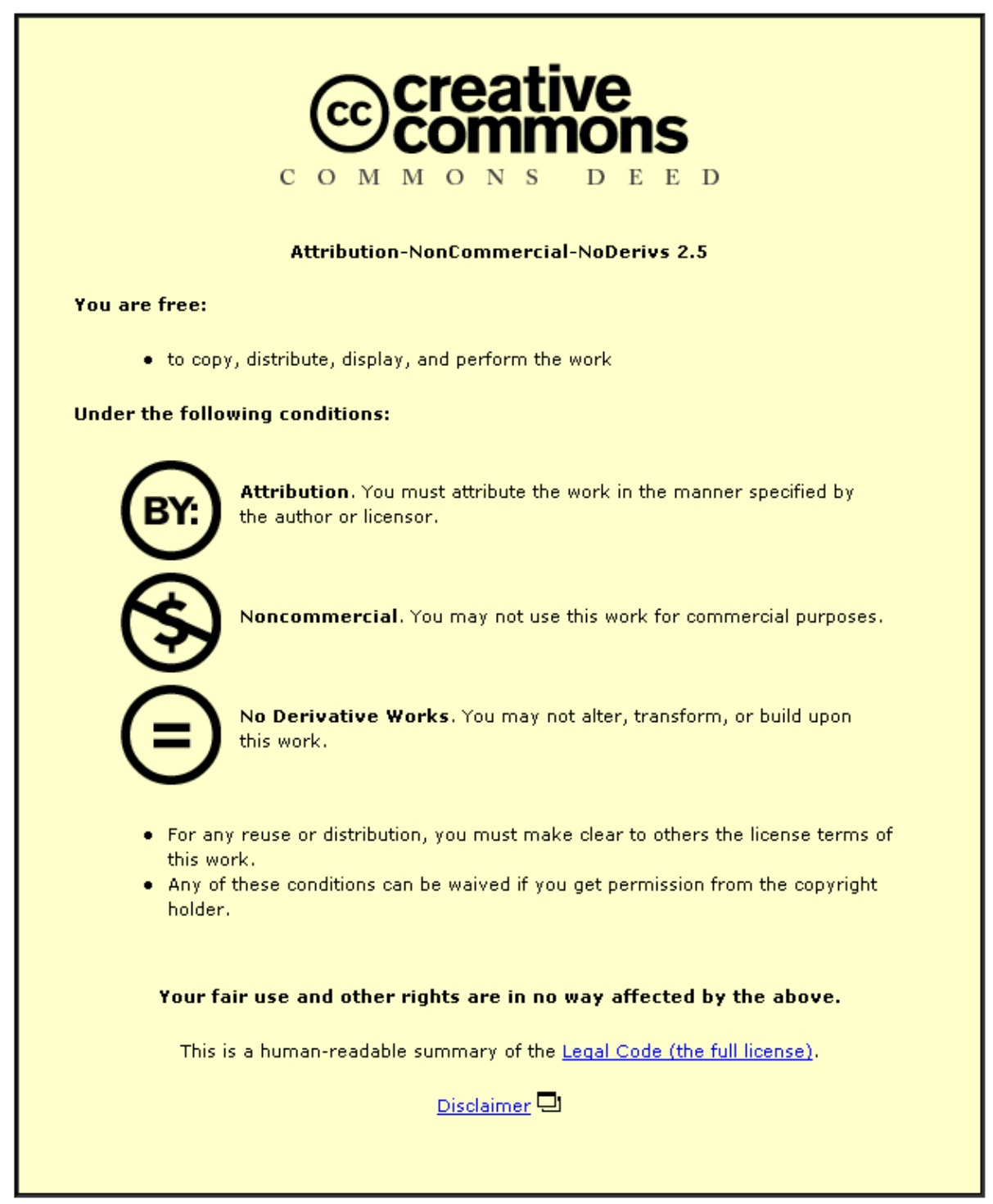

For the full text of this licence, please go to: http://creativecommons.org/licenses/by-nc-nd/2.5/ 


\title{
Enterprise Design Information: The Key to Improved Competitive Advantage \\ By
}

\author{
J A Harding and K Popplewell, \\ Dept of Manufacturing Engineering, \\ Loughborough University, Loughborough, Leicestershire, UK.
}

\begin{abstract}
:
Changes occur very quickly within competitive business environments, and successful companies need to respond quickly by producing and delivering improved products and services, or by changing their business strategies and operational systems. Such changes may require redesign of resources, processes, strategies or organisational structures within the enterprise. Redesign is an expensive and risky process. This paper reports on how information models, databases and support tools, can be used to reduce uncertainty, by modelling the desired enterprise, and predicting its performance, before costly physical implementations are undertaken. Thus management can gain valuable insight into the potential efficiency and performance capabilities of the redesigned enterprise, and minimise the risks associated with change. An overview is provided of an information-centred, multi-view design system to facilitate and accelerate the design or redesign of manufacturing enterprises. The design system includes both an information model, to store details of the proposed enterprise, and multiple design tools to support both the building and evaluation of the model. The design tools enable the model to be viewed in different ways, thus emphasising and clarifying particular aspects of the design, and enabling the potential performance of the designed enterprise to be predicted.
\end{abstract}

Key words: Enterprise Design, Information Modelling, Performance Driven Design

\section{Introduction}

To successfully compete in business, manufacturing enterprises must achieve sustainable positions in their environment, despite ever-increasing competition in the market. Hence management needs to identify goals and objectives for their business, and implement effective strategies which enable their manufacturing function to contribute to the long-term competitiveness and performance of the business. Changes can occur very quickly within the competitive business environment, so companies must be able to respond quickly by producing and delivering products which customers want, at prices customers are willing to pay. To meet these requirements, the manufacturing function must be flexible, and open to change. Additionally, changes in competitive strategies may be necessary to make the benefits provided by products more visible. Thus management must be able to assess the requirements of the competitive environment, and use this to drive change within the enterprise, to ensure that required performance levels are attained.

The competitive forces described above may drive changes within the processes, resources, strategies, or organisational structure of the manufacturing enterprise, and redesign should be accomplished quickly and with a minimum of disruption to business. Modifying a manufacturing enterprise is equivalent to designing and building a very valuable product, and if errors are made, they can badly affect the company's market position, and can be so costly that the organisation does not survive to attempt a second redesign. Also, to ensure the redesign is really effective, and fulfils its objectives, once the enterprise design has been implemented and the new factory is operational, management needs to critically monitor that predicted performance levels are 
achieved in practice, and continue to be achieved. Feedback of this type is essential to improve competitive performance, and in addition, to act as a driver for future enterprise redesign.

Effective information collection and analysis is critical for successful enterprise design, since if a proposed design can be tested and evaluated before it is implemented, costly mistakes can be avoided. Information models, databases and support tools, can be used to model the desired enterprise, and predict its performance. Thus models of the designed enterprise can be used to provide very valuable insight into potential efficiency and performance capabilities. Collection and analysis of comprehensive, accurate information from across the organisation and markets can provide management with a better understanding of how changing demands affect their business, of what the market requires, and of what strategies should be adopted to cope with the demand.

This paper reports on how an information-centred, multi-view design system can facilitate and accelerate the enterprise design process. In this context, enterprise design covers a wide range of activities, from redesigning a production cell in order to manufacture a new product efficiently, to designing a new factory on a green field site. The factory design system, which is described in section 2, has two main components, (1) an information model, called the Factory Data Model (FDM) and (2) design and evaluation tools, called Factory Design Process (FDP) Views. The FDP approach and prototype tools have been tested through several industrial case studies.

In conclusion, this paper also considers future work, and an information driven, performance assessment based extension to the design system is proposed.

\section{Information-Centred Enterprise Design}

\subsection{Background}

A manufacturing enterprise is a highly complex entity, and a designer must fully understand the activities of the enterprise and the operation of its business, and business environment, in order to produce a satisfactory design. It is necessary to understand both the current and future desired positions of the organisation, as well as the discrepancy between them (Glykas \& Valiris, 1998). Enterprise models can be used to test whether proposed enterprise designs can achieve a particular type or level of performance, before expensive implementation is undertaken. Enterprise modelling captures the desired system as information, and in this research, the enterprise model is termed the Factory Model. Many architectures and frameworks have been proposed for enterprise modelling (Bravoco \& Yadav, 1985a, 1985b) including ARIS (Scheer, 1992), GRAI-GIM (Doumeingts, 1993), CIMOSA (ESPRIT project 688/5288, 1993), and PERA (Williams, 1993).

In order to collect and store the information which comprises an enterprise model, the characteristics of the enterprise have been examined in detail, and in various ways. Each way of analysing, interpreting or examining the enterprise may expose different characteristics or behaviours of the enterprise, and is termed as taking a View of the enterprise. Thus different Views enable the model to be looked at from different perspectives, and with different priorities, and thus aid users to identify and clarify particular aspects of the desired enterprise. The views included in individual architectures vary, e.g. CIMOSA defines four different views which focus on different aspects of the model, these are Function, Information, Resource and Organisation (Molina Gutierrez, 1995) (Jorysz \& Vernadat, 1990(a) 1990(b)). Detailed comparison of enterprise modelling methodologies and modelling constructs involving CIMOSA can be found 
in Kosanke (1996) and Vernadat (1997), and a comparison of a top down methodology (CIMOSA) and bottom up approach to manufacturing enterprise engineering is provided by Edwards et al (1998).

Several views are often included in architectures, since multi-view approaches are believed to provide the knowledge necessary for accurate and correct understanding of the system, (Wang et al, 1993) (Bouti \& Ait Kadi, 1998). Generally a function view is included in all architectures, but other views, such as decision, behaviour or control views are only covered in some architectures. There are also many commercially available software systems and tools to support Enterprise Resource Planning, Business Process redesign, and operational activities of the enterprise (SAP, 1999) (BAAN, 1999) and (BWU, 1999). These provide valuable support to the enterprise in operational and planning activities, but they are not ideal to support enterprise design, or redesign, particularly in its conceptual stages. Existing approaches to Business Process Reengineering do not necessarily support understanding of the organisation's strategy, business structure and processes, (Glykas \& Valiris, 1998). Design is an innovative process in which system requirements need to be identified and clarified progressively throughout the design process. Existing tools can facilitate the building of a descriptive information model, to improve enterprise IT systems (Wright \& Burns, 1996) (Klein, 1994). In practice, business process redesign projects often fail because tools lack support for capture of knowledge throughout the redesign cycle (Earl et al, 1995) (Thomas, 1996).

\subsection{Factory Design Process System}

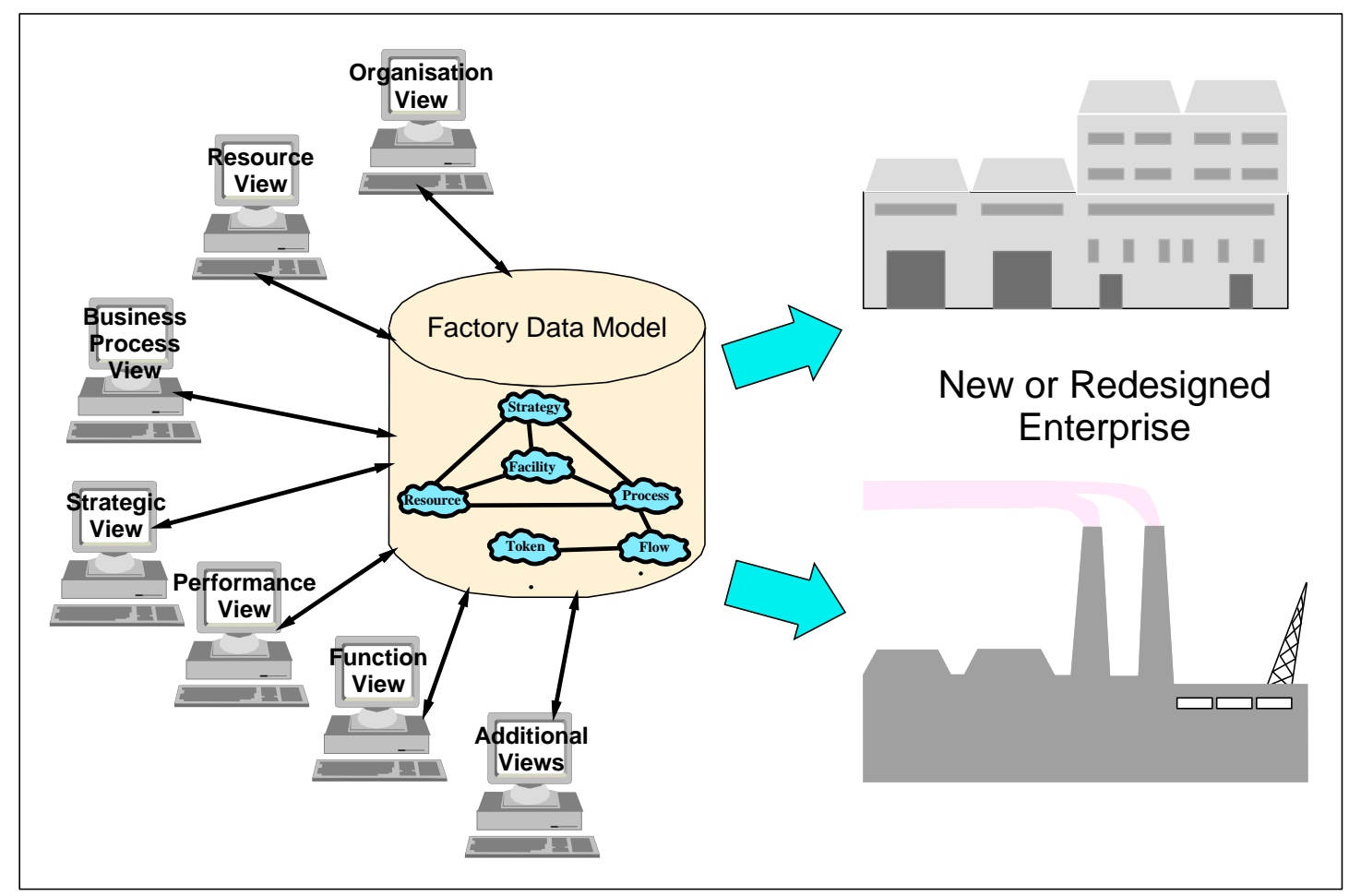

Figure 1: Factory Design Process System

A comprehensive, information-centred method to support manufacturing enterprise design has been researched through the Factory Design Process (FDP) Project ${ }^{1}$. The FDP approach to enterprise design enables designers and management to gradually build a progressively more detailed enterprise design, starting from very simple partial models. The FDP system is represented in figure 1. The FDP approach includes a set of six core Views, i.e. Strategic,

\footnotetext{
${ }^{1}$ The Factory Design Process Research is an EPSRC funded project under grant GR/L09301
} 
Function, Business Process, Organisation, Resource, and Performance. They are described in detail in Yu et al 2000(a), and their application demonstrated through a case study in Harding et al, 1999(a). However, a brief overview of each is given below.

Strategic View - Assists designers to clarify business aims and objectives, and thereby to identify, collect and analyse appropriate strategies. Supports identification and recording of operational rules to improve business performance.

Organisation View - Assists designers to describe the organisation structure of an enterprise in terms of a hierarchy.

Function View - Assists designers to identify and describe what the enterprise does, and thus enables the business functions to be captured and assessed.

Business Process View - Enables designers to expose interactions between a group of processes, and further to investigate their performance.

Resource View - Helps designers to identify and collect resource information, and to analyse the utilisation of resources and productivity.

Performance View - Assists designers to evaluate their design, and determine whether the proposed enterprise can satisfy the identified objectives. Two types of evaluation are used. Static evaluation uses performance metrics, which are fixed or static at any given time. Dynamic evaluation uses simulation technology, to experiment with 'what-if' scenarios.

The above represent core views, which form an essential part of the FDP system. However, this set is not exhaustive, and the FDP system also allows for the inclusion of additional views to satisfy particular design requirements. In this research, Views can be used to gather information and populate it into the Factory Model (within the database) and to analyse and evaluate a design represented by a Factory Model.

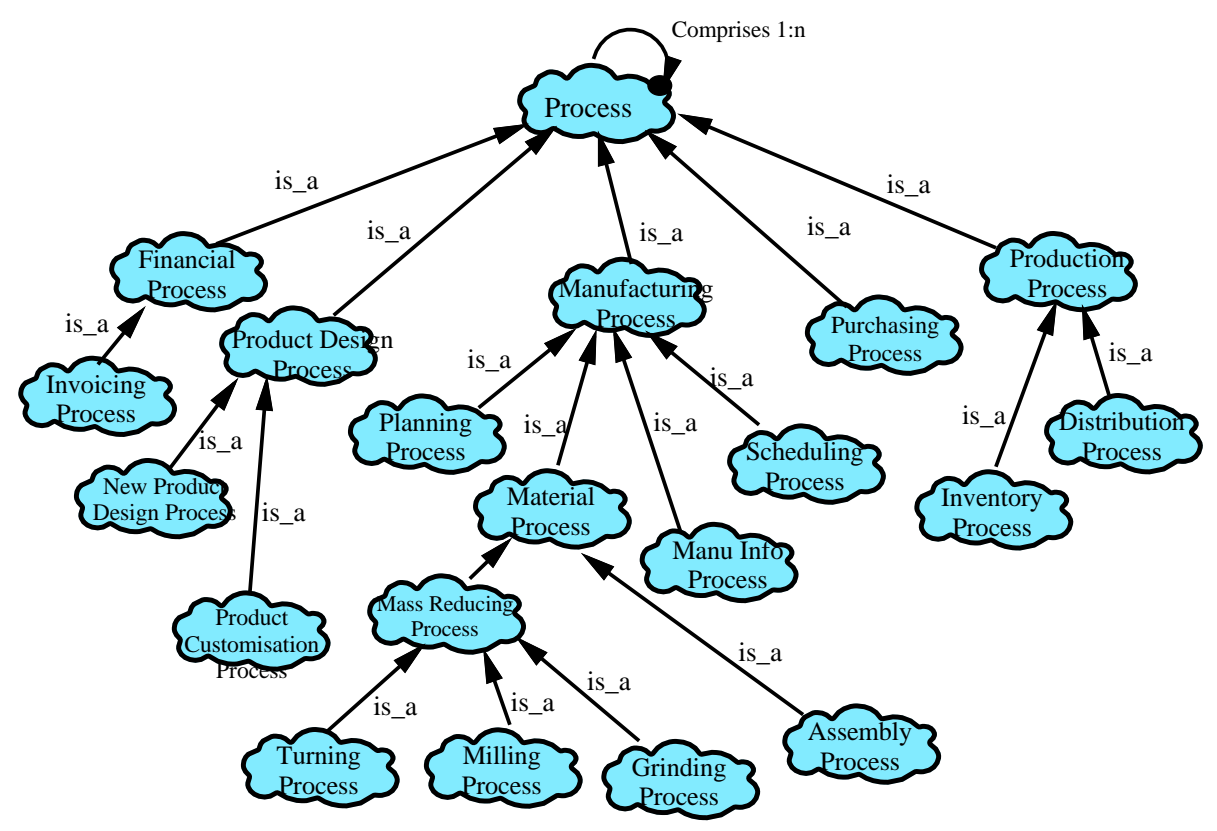

Figure 2: Selected Classes from Process Hierarchy 
At the centre of the FDP approach is an information model, called the Factory Data Model (FDM) ( $\mathrm{Yu}$ et al, 2000(b)). The FDM provides a data structure for the Factory Models. The FDM is comprised of 6 key information class hierarchies that represent essential elements of any manufacturing system. The base classes of the hierarchies are Resource, Process, Strategy, Facility, Token and Flow, as shown on the factory data model in figure 1. The class hierarchies can be very large, ranging from high level, general objects to low level, specialised, highly detailed objects. For example, a small section of the Process class hierarchy is shown in figure 2. This figure shows that at a high level of abstraction, there are processes such as Purchasing Process, Design Process and Manufacturing Process, whilst at the lower levels, more detailed, specialised Manufacturing Fabrication processes exist, such as Milling and Turning. Using the FDM, an enterprise design can be captured in a database and information can be added, modified or removed gradually, so that progressively more detailed information defining the desired enterprise is obtained. Since a database is used, the design information can easily be shared between the FDP Views (Harding et al, 1999(a)).

An essential aspect of the FDP approach is that developing designs can be regularly checked and their performance evaluated against strategic plans so that management can be confident that the proposed factory will meet business objectives. The Performance view adopted during the FDP research is capable of both static and dynamic evaluation of system performance, within a limited set of metrics. Metrics such as lead-time and cost, are classified as static performance measures, since values can be calculated for them at any given time. Dynamic evaluation of the model is also an important element of the Performance view, since some decisions are better based on a good understanding of how the system will behave during operation (Yu et al, 1998(a)) (Harding and Popplewell, 2000). During the experiments and case studies, dynamic evaluation has been carried out using simulation technology, and Arena simulation software (Kelton et al, 1998). Experience has shown that there is no fixed order in which the FDP Views should be considered, and each View may be applied many times during the design process. However, in order to obtain a good design it is essential that the objectives of the design be clearly defined, and that the performance requirements of the proposed enterprise be established. Hence a Strategic View of the enterprise must be taken early in the design process.

\section{Performance Driven Design}

As previously discussed, there are several reasons why redesign of the enterprise may be necessary, and these include changes in competitive forces, new product introductions, or changes in business objectives. In all cases, it is important that management and designers have an understanding of the existing business position and future desired positions, as well as the discrepancy between them, the enterprise's competitive environment, and the objectives of the design, e.g. what performance is expected from the proposed enterprise, and what metrics are to be used to measure success or failure. These aspects are examined and developed through taking a Strategic View of the design.

A matrix based tool has been developed to support the Strategic View of the Enterprise. Early research into manufacturing strategy (Adams \& Swamidass, 1989) (Anderson, Cleveland and Schroeder, 1989) indicated that there are two separate aspects, (1) the process for formulating and/or implementing the manufacturing strategy (Hill, 1993) and (2) the core content of the manufacturing strategy. A Strategic View Support tool therefore requires both the knowledge of how a strategy can be formulated, and the use of reliable information related to the manufacturing position of a firm. Several types of information are therefore concerned, 
- knowledge of strategy formulation and relationships between critical success factors,

- the content and critical factors of manufacturing strategy,

- information of the capability and capacity of the manufacturing system, and

- information relating to the enterprise's competitive environment.

The prototype Strategic View Support tool considered during this research has been built in Excel, and this approach enables the user to handle large amounts of both quantitative data and qualitative items. The tool is programmed with variables and operational rules, which may be used for business (at management level) and manufacturing functions (at the operational level). However, as the core content of strategy is largely individual to a particular enterprise, the actual values and types of information items which appear on each matrix can be modified by the user, to suit the needs of their manufacturing enterprise. The default (or initial) information types on the matrices represent some critical success factors (CSF). These may include costs, capacity and size of plant, product throughput, efficiency, working hours profile, materials input/output/storage metrics, productivity or reliability ratings which are associated with achieving particular manufacturing objectives, such as cost and waste reduction.

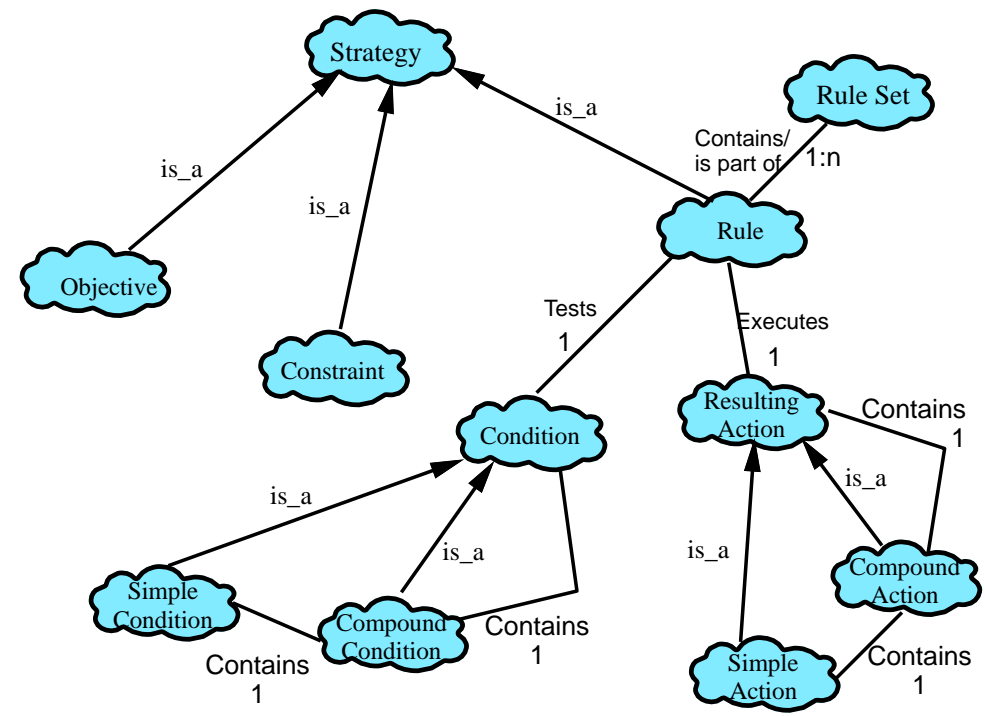

Figure 3: Part of the Strategy Class Hierarchy

As previously mentioned, it is important to understand both the existing business position and future desired positions, as well as the discrepancy between them. The two sets of values can be entered in the matrices for each CSF, in order to capture the current position of the enterprise against where it wants to be (i.e. its objectives). These can be clearly presented in adjacent columns, using the matrix approach. Information items can also be linked by rules, which may be customised by the user. It has been shown that there are several different types of linkages, or relationships between competitive priorities and the establishment of manufacturing objectives (Kim and Arnold, 1996). The variables in the matrices can therefore be linked to capture different relationships, by rules appropriate to the individual enterprise. Rules can assist in either the analysis of current and future position or in strategic appraisal and formulation. Knowledge of strategy formulation and relationships between critical success factors is therefore available through customisation and rules in the Strategic View Support tool. The Strategic View Support tool helps clarify and identify business aims and objectives and strategies, and these are then stored within the Factory Model, using objects from the Strategy class hierarchy, see figure 3.

A factory design is gradually achieved by using each of the core FDP Views to focus on different aspects of the required enterprise (as demonstrated by the above discussion on use of the 
Strategic View). Examples of the iterative use of views to generate a design are given in Harding et al 1999 (a) and (b). By using the core views to identify and satisfy the requirements of the design, information describing the capability and capacity of the proposed manufacturing system is gathered and stored within the Factory Model, using objects from the 6 key information class hierarchies mentioned above. The process class and its subclasses describe transformations, which can be performed. A process may be executed using resources, and is carried out, or controlled by strategies. The resource class and its subclasses describe mechanisms that enable a process to be executed, e.g. skilled operators, manufacturing or related equipment. The strategy class and its subclasses capture knowledge and methods used to define objectives, control aspects of the enterprise, and make decisions. The facility class enables processes and resources to be arranged within the organisation structure, for example, into factories, departments, shops, stations, etc. A system is a group of connected processes, with a purpose. Relationships between processes are described using the flow class. The state of a flow object is determined by the token objects it is carrying, e.g. components, assemblies, documents or instructions, and the processes which the flow connects.

It can be argued that successful performance is really an issue of fit between the external market and the characteristics of the organisation, hence in order to design an enterprise which will perform efficiently and effectively consideration must also be given to the competitive environment. Information relating to the enterprise's competitive environment, covers a very wide scope, and is available to management and designers from a number of sources. Since the manufacturing strategy is closely related to other strategies such as Marketing (Gupta, Lonial and Mangold, 1991) and Finance (Hill, 1993) (Drury, 1992), this information and knowledge must also be captured. Performance of the production system, when a new product is introduced, can also be analysed, and it has been shown that the matrix-based modelling tool can also be linked to more detailed mathematical modelling to examine, for example the impact of introduction of new products. (Yu et al, 1998(b)). When predicting the performance of the enterprise design in operation, it is usually necessary to consider products (for example, production of products or fulfilment of orders). Details of individual products, from concept through to disposal, may be captured in product models (Krause et al, 1993) and it has been shown that these can successfully be extended to include, interpret and analyse information relating to customer needs (Harding et al, 2000) (Omar et al, 1999). The extended model introduced by Omar et al also begins to address the need to store competitor information.

As the design progresses, it must be evaluated to check that it can satisfactorily meet the objectives and requirements of the design. The potential performance of the proposed factory may be assessed through static and dynamic evaluation of the model, using the Performance View. Simulation systems have been shown to be valuable elements of the Performance View, (Harding \& Popplewell, 2000). Simulation models may be built using information from the factory model, and then experiments run to test whether the objectives, or desired position can be achieved by the proposed design. For example, if a CSF identified by the Stategic View, was product throughput, and the desired position was an increase of $15 \%$ per period, simulation runs may be used to test whether the model representation of the proposed factory could achieve this increase. In this way, the performance of the proposed design can be predicted, and information saved to provide a snapshot of predicted performance for future reference. Once a design is actually implemented, it is proposed that actual performance achieved through operation may be measured against these snapshots

\section{Conclusions and Further Work}


This paper provides an overview of the results of the Factory Design Process Research. An information centred, iterative approach to enterprise design is described, and an overview is given of the main elements of the FDP System, i.e. a reusable data structure, termed the Factory Data Model, and the six core, integrated Views. The FDP approach to enterprise design enables designers and management to gradually build, and evaluate, a progressively more detailed enterprise design, by using FDP Views, starting from very simple partial models.

Performance issues and the competitive environment are drivers for enterprise redesign. The Strategic and Performance Views were therefore selected to demonstrate aspects of this research, in this paper. The importance of establishing design objectives through the Strategic View, and progressively evaluating the design, against these objectives, using the Performance View, has been discussed. As all aspects of the design are stored within a database, including outputs from both Strategic and Performance View analysis, valuable information is available to, and may be shared between, management and design team members throughout the design process. The factory model produced during the design stage provides a valuable information source for the subsequent operation of the enterprise. Enterprise designs may be refined, or the need for further design or redesign identified through analysis of actual factory performance achieved, against snapshots of the predicted performance from the design stage. The relationships between elements of the FDP System, and associated information models, including product models and performance models, which may include valuable information relevant to the competitive environment, has also been introduced.

It is proposed that information gathered during this design stage, including the predicted performance of the manufacturing system, continues to be valuable to the enterprise, once the design is implemented and operational. Further work is required in this area, particularly to include research into a Performance Information model. It is proposed that a Performance Information Model would be valuable for two reasons. Firstly, to capture details of predicted performance for the redesigned enterprise, so this can be used as a benchmark for future factory operation, and secondly to facilitate collection and analysis of enterprise performance during operation. By storing information relating to actual performance during operation, snapshots of the achieved performance can also be collected over a period of time, as shown in figure 4.

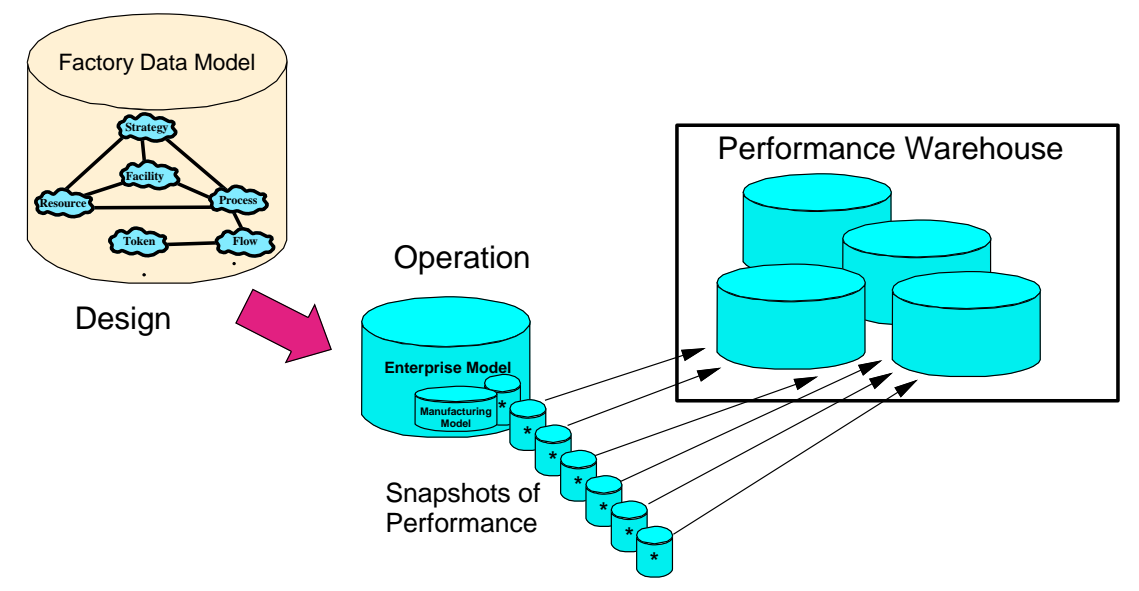

Figure 4: Performance Evaluation through Factory Operation

Analysis of these snapshots of actual factory performance, achieved over a period of time, against the benchmark performance which was predicted at the design stage, could provide valuable insights into the true state of the enterprise. Evaluation of predicted performance against 
achieved performance would also provide management with valuable knowledge and understanding on which to base decisions for design refinement and future enterprise design or redesign.

\section{References}

Adams, E E Jr and Swamidass, P M, (1989), Assessing operations management from a strategic perspective. Journal of Management, 15:2, 181-203.

Anderson, J, Cleveland, G and Schroeder, R G, (1989), Operations strategy: A literature review. Journal of Operations Management, 8:2, 133-157.

BAAN, (1999), http://www.ac.com/services/baan/baan_home.html, web page of Andersen Consulting, Baan Services,

Bouti A. and Ait Kadi, D., (1998), Capturing Manufacturing System Knowledge Using MultiView Modelling, Int. J. Computer Integrated Manufacturing, Vol. 11, No. 1, pp. 77 -93.

Bravoco, R. R. And Yadav, S. B., (1985a), Requirement Definition Architecture - An Overview, Computers in Industry, Vol 6, pp. 237-51.

Bravoco, R. R. And Yadav, S. B., (1985b), A Methodology to Model the Functional Structure of an Organisation, Computers in Industry, Vol 6, pp. 345-61.

BWU, (1999), http://www.bwu.org, web page of BAAN World Users.

Doumeingts, G., Chen, D., Vallespir, B. and Fenie, P., (1993), GIM (GRAI Integrated Methodology) and its Evolutions - A Methodology to Design and Specify Advanced Manufacturing Systems, Proceedings of the JSPE/IFIP TC5/WG5.3 Workshop on the Design of Information Infrastructure Systems for Manufacturing, DISM'93, Tokyo, Japan, 8-10 November, Yoshikawa, H. And Goossenaerts, J. (Ed.), North-Holland, pp. 101-17.

Drury, J C, (1992), Management and Cost Accounting (Chapman \& Hall, London).

Earl, M J, Sampler, J L, and Short, J E, (1995), Strategies for business process reengineering: evidence from field studies, Journal of Management Information Systems, 12(1), pp 31-56.

Edwards J M, Aguiar M W C and Coutts I A (1998), 'Top down and bottom up approach to manufacturing enterprise engineering, using the function view', International Journal of Computer Integrated Manufacturing, Vol 11 No 4, pp.p 364-376.

ESPRIT Project 688/5288, (1993), CIMOSA: Open System Architecture for CIM, AMICE, Volume 1, ESPRIT Consortium AMICE (Ed.), $2^{\text {nd }}$, revised and extended edition, SpringerVerlag.

Glykas M, and Valiris G (1998), 'Management science semantics for object-oriented business modelling in BPR', Information and Software Technology, Vol 40, No 8, pp.p 417-433

Gupta, Y P, Lonial, S C and Mangold, W G, (1991) An examination of the relationship between manufacturing strategy and marketing objectives. International Journal of Operations and Production Management, 11:10, 33-43.

Harding J A and Popplewell K, (2000), 'Simulation: An Application of Factory Design Process Methodology', Journal of the Operational Research Society, ISSN 0160-5682, 51, pp 440-448.

Harding, J A, Yu, B, and Popplewell, K, (1999(a)) 'Information Modelling: An Integration of Views of a Manufacturing Enterprise', International Journal of Production Research, ISSN 0020 7543, 37(12), pp 2777-2792.

Harding, J A, Yu, B, and Popplewell, K, (1999(b)), 'Organisational and Functional Views of a Small Manufacturing Enterprise', Journal of Business Performance Management, ISSN 13684892, 1(3), pp 338-352.

Harding, J A, Popplewell, K, Fung, R Y K and Omar, A R, (2000) 'An Intelligent Information Framework for Market Driven Product Design', accepted by Computers in Industry, ISSN 0166 3615, awaiting final publication details.

Hill, T, (1993), Manufacturing Strategy - The Strategic Management of the Manufacturing Function (Macmillan, London), Second edition. 
Jorysz H R and Vernadat F B, (1990(a)), CIM-OSA Part 1: total enterprise modelling and function view, International Journal of Computer Integrated Manufacturing, Vol 3, Nos.3-4, pp 144-156.

Jorysz H R and Vernadat F B, (1990(b)), CIM-OSA Part 2: information view, International Journal of Computer Integrated Manufacturing, Vol 3, Nos.3-4, pp 157-167.

Kelton W D, Sadowski R P and Sadowski D A, 1998, Simulation with Arena, WCB McGrawHill, ISBN 0-07-027509-2

Kim, J S and Arnold, P, (1996), Operationalizing manufacturing strategy: An exploratory study of constructs and linkage, International Journal of Operations and Production Management, Vol 16, No. 12, pp 45-73.

Klein, M M, (1994), Reengineering methodologies and tools, Information System Management, Spring pp30-35

Kosanke, K., (1996), Comparison of Enterprise Modelling Methodologies, In Goossenaerts, J., Kimura, F. and Wortmann, H. (eds) Proceedings of the IFIP TC5/WG5.3/WG5.7 International Conference on the Design of Information Infrastructure Systems for Manufacturing (DIISM'96), (Chapman and Hall), 115-127.

Krause, F L, Kimura, F, Kjellberg, T, Lu, S C Y, (1993), Product Modelling, Annals of the CIRP Vol 42, 2, pp695-706

Molina Gutierrez, A, (1995), A Manufacturing Model to Support Data-Driven Applications for Design and Manufacture, PhD Thesis, Dept of Manufacturing Engineering, Loughborough University, UK.

Omar, A R, Harding, J A, and Popplewell, K, (1999), Design for Customer Satisfaction: An Information Modelling Approach, Integrated Manufacturing Systems, (The International Journal of Manufacturing Technology Management) ISSN 0957-6061, 10(4), pp 199-209.

SAP, 1999, Web page of SAP Industry Solutions, http://www.sap.com.

Scheer, A W, (1992), Architecture of Integrated Information Systems: Foundations of Enterprise Modelling, Springer-Verlag, Berlin.

Thomas, C C (1996) Business process re-engineering: myth \& reality, Kogan Page, London.

Vernadat, F.B., (1997), Business Process Modelling: Comparing IDEF3 and CIMOSA, ReEngineering for Sustainable Production, Proceedings of the OE/IFIP/IEEE International Conference on Integrated and Sustainable Industrial Production, Lisbon, Portugal, 297-307.

Wang, W, Popplewell, K and Bell, R, (1993), An Integrated multi-view system description approach to approximate factory modelling, International Journal Computer Integrated Manufacturing, 6(3) pp165-174.

Williams, T, (1993), The Purdue Enterprise Reference Architecture, Information Infrastructure Systems for Manufacturing (B-14), Yoshikawa, H and Goossenaerts, J, (Ed), Elsevier Science B. V. (North-Holland) pp 43-51.

Wright, D T and Burns, N D, (1996), Guide to using the WWW to survey BPR research, practitioners and tools, IEE Engineering Management Journal, Vol 6, No 5, pp211-216.

Yu, B, Harding, J A, and Popplewell, K, (2000(a)), 'Supporting Enterprise Design through Multiple Views of a Common Neutral Model', International Journal of Agile Management Systems, ISSN 1465-4652, 2(1), pp 71-82.

Yu, B, Harding, J A, and Popplewell, K, (2000(b)), 'A Reusable Enterprise Model', International Journal of Operations Management, ISSN 0144-3577, 20(1), pp 50-69.

Yu, B, Harding, J A, and Popplewell, K, (1998(a)), Enterprise Design: A Case Study Using Factory Design Process Methodology, Factory Design Process Research Group Report, Dept of Manufacturing Engineering, Loughborough University, UK.

Yu, B, Harding, J A and Popplewell, K, (1998(b)), Supporting Strategy Development in New Product Introduction, Proceedings of the World Innovation \& Strategy Conference, Sydney Australia, 2-5 August, 1998, edited by R L Chapman and R Hunt, pp 569-576, ISBN 1-87576097-0 